University of Nebraska - Lincoln

DigitalCommons@University of Nebraska - Lincoln

\title{
Three-dimensional modeling of carbon/epoxy to titanium single- lap joints with variable adhesive recess length
}

\author{
Yi Hua \\ University of Nebraska-Lincoln \\ Linxia Gu \\ University of Nebraska-Lincoln, gul@fit.edu \\ Michael Trogdon \\ University of Nebraska-Lincoln
}

Follow this and additional works at: https://digitalcommons.unl.edu/mechengfacpub

Part of the Mechanical Engineering Commons

Hua, Yi; Gu, Linxia; and Trogdon, Michael, "Three-dimensional modeling of carbon/epoxy to titanium single-lap joints with variable adhesive recess length" (2012). Mechanical \& Materials Engineering Faculty Publications. 63.

https://digitalcommons.unl.edu/mechengfacpub/63

This Article is brought to you for free and open access by the Mechanical \& Materials Engineering, Department of at DigitalCommons@University of Nebraska - Lincoln. It has been accepted for inclusion in Mechanical \& Materials Engineering Faculty Publications by an authorized administrator of DigitalCommons@University of Nebraska Lincoln. 


\title{
Three-dimensional modeling of carbon/epoxy to titanium single-lap joints with variable adhesive recess length
}

\author{
Yi Hua, ${ }^{1}$ Linxia Gu, ${ }^{1,2}$ and Michael Trogdon ${ }^{1}$ \\ 1. Department of Mechanical and Materials Engineering, University of Nebraska-Lincoln, Lincoln, NE 68588-0656, USA \\ 2. Nebraska Center for Materials and Nanoscience, Lincoln, NE 68588-0656, USA \\ Corresponding author - L. Gu, Department of Mechanical and Materials Engineering, University of Nebraska-Lincoln, \\ Lincoln, NE 68588-0656, USA; tel 402 472-7680, fax 402 472-1465, email lgu2@unl.edu
}

\begin{abstract}
The objective of this paper was to investigate the performance of recessed single-lap joints with dissimilar adherends through the finite element method. The influence of material and geometric nonlinearity of the adhesive as well as the impact of the recess length was examined in terms of maximum principal stresses. The strength of the joint was obtained as the load to initiate the crack propagation. Results suggested that either adding a spew fillet or considering the adhesive plasticity led to reduced peak stresses at the edge of the adhesive layer. The presence of a spew fillet in the single-lap joint with a recess length of $50 \%$ of the overlap length reduced the peak stress concentrations in the adhesive layer by $45.2 \%$ and subsequently improved the strength of the joint by $36.3 \%$. Mitigation of stress concentration was observed in cases of an adhesive layer with a smaller recess length. The strength of recessed joints with a gap less than $50 \%$ of the overlap length decreased slightly. For the recess length as $70 \%$ and $90 \%$ of the total overlap length, the strength of the joints reduced $36.4 \%$ and $66.3 \%$, respectively. This study suggested a recess of less than $50 \%$ of the overlap length may be beneficial for the performance of the joints.
\end{abstract}

Keywords: recess, single-lap joints, stress analysis, crack initiation, finite element method

\section{Introduction}

Adhesively bonded structure joints have emerged as one of the primary means of bonding in response to the demand for lightweight, high-strength, low-cost products, especially in the automotive and aerospace industries. Recessed adhesive joints, i.e. a gap in the center portion of the adhesive within the overlap, were proposed as one of the bonding techniques with the same performance as the continuous joint [1]. Although continuous adhesive joints have been extensively studied [2-6], the analysis of recessed adhesive joints is lacking in the literature. For example, Rossettos and his co-workers $[7,8]$ have shown that the shear stresses were hardly affected by a central void size up to $70 \%$ of the overlap length for singlelap joints. If the void was located closer to the overlap ends, $20 \%$ variations of maximum shear stresses were observed. Olia and Rossettos [9] performed an analytical study on the effects of gaps in single-lap joints subjected to combined axial and bending loads. Their results showed that the presence of a gap led to high peel stresses at the free edges. However, if the gap was centrally located, the peel stresses at the outside edges increased only slightly as compared to the case without the gap. The shear stresses remained essentially unaffected at distances far from the gap. Mazumdar and Mallick [10] conducted static tensile tests on single-lap joints with varied de- grees of recess, which showed that the average failure load did not change with increased recessing. Lang and Mallick [1] numerically studied recessed bonded joints with a spew fillet. Their results showed that the maximum stress remained near the adhesive spew terminus and increased only slightly with an increased level of recessing. The existing numerical studies in the recessed adhesive joints focused on the stress analysis in the two-dimensional (2D) case. However, the in-plane tension on the single-lap joint would develop complicated three-dimensional (3D) stresses, such as out-of-plane bending, which could not be captured in the 2D modeling.

In this work, 3D finite element models of recessed singlelap joints were developed. 3D stress distributions in the adhesive were obtained. The influence of material and geometrical properties of the adhesive as well as the impact of the recess length was examined in terms of maximum principal stresses. The crack initiation load predicted by extended finite element method (XFEM) [11,12] was used to evaluate the strength of the recessed joints.

\section{Finite element modeling}

A 3D model of the recessed single-lap joint was developed using commercial finite element software ABAQUS (Dassault Systems Simulia Corp., RI, USA). Figure 1 presented 

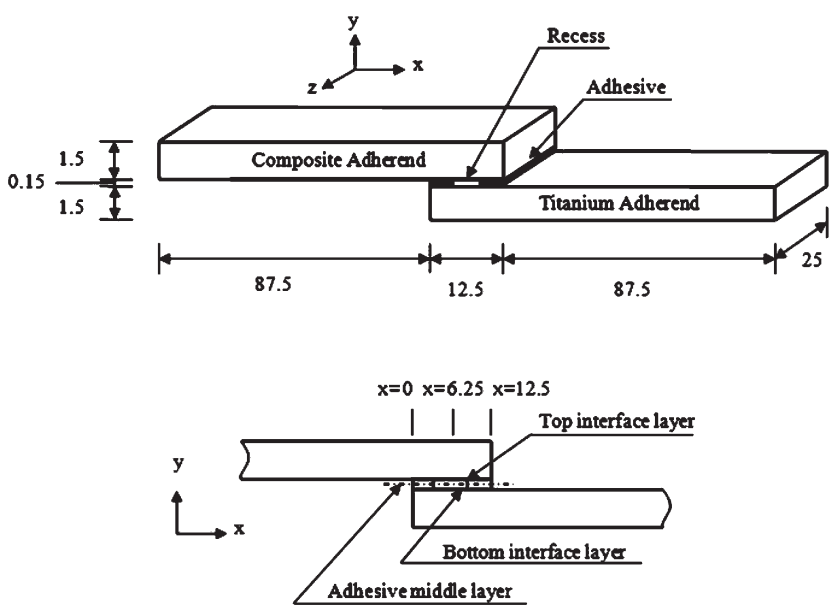

Figure 1. Recessed single-lap dissimilar joint with dimensions in $\mathrm{mm}$.

the dimensions and material properties of the single-lap joint with the recess length as $50 \%$ of the overlap length. The overlap length between two adherends is fixed as $12.5 \mathrm{~mm}$ in this work. The carbon/ epoxy adherend $(0 /+45 /-45 / 0)$ was characterized by orthogonal elastic moduli $E_{1}=147 \mathrm{GPa}, E_{2}=E_{3}=10.3 \mathrm{GPa}$, shear moduli $G_{12}=G_{13}=7 \mathrm{GPa}, G_{23}=3.7 \mathrm{GPa}$, and Poisson's ratio $v_{13}=v_{23}=0.27, v_{12}=0.54$. The material properties for the titanium adherend were $E=116 \mathrm{GPa}$ and $v=0.33$. The FM73 adhesive cured at $120^{\circ} \mathrm{C}$ [13] was used for bonding with isotropic properties $E=1100 \mathrm{MPa}, \mathrm{G}=382 \mathrm{MPa}$ and $v=0.44$.

The model was meshed with reduced 8-node hexahedral elements (C3D8R). A fine mesh was used at both the overlap ends. A mesh convergence test has been conducted and the minimum mesh size was chosen as $0.05 \mathrm{~mm}$. The left end of the composite adherend was constrained in all degrees of freedom while a $120 \mathrm{MPa}$ tensile load was applied along the $x$-direction on the opposite edge of the titanium adherend. Perfect adhesion was assumed on the interfaces between adhesive layer and adherends. Furthermore, the extended finite element method (XFEM) coupled with the cohesive traction separation law [12-14] has been used to evaluate the strength of the recessed joints.

\section{Results and discussions}

\subsection{FE model validation}

A continuous titanium-titanium joint subjected to $10 \mathrm{MPa}$ tensile load was used to validate the numerical model against the analytical solutions obtained from both the Volkersen shear lag equation [15] and the classical Goland and Reissner (G-R) solution [16]. The shear stress in a single-lap joint can be calculated from the Volkersen equation as follows:

$$
\begin{aligned}
\tau & =\frac{F \omega \cosh (\omega x)}{2 b \sinh \left(\omega_{l} / 2\right)}+\frac{F \omega \sinh (\omega x)}{2 b \cosh \left(\omega_{l} / 2\right)}\left[\frac{E_{2} t_{2}-E_{1} t_{1}}{E_{2} t_{2}+E_{1} t_{1}}\right] \\
\omega & =\sqrt{\frac{G}{\eta}\left[\frac{\left.E_{2} t_{2}\right) E_{1} t}{E_{2} t_{2} E_{1} t}\right]}
\end{aligned}
$$

where $F$ is the applied tensile force, $b$ is the width of the adhesive, $l$ is the length of the overlap, $G$ is the shear modulus of the adhesive, $\eta$ is the thickness of the adhesive layer, and $E_{1}, E_{2}, t_{1}$, and $t_{2}$ are the Young's modulus and thickness of the top and bottom adherends, respectively. It is worth noting that if the thickness and Young's modulus for the adherends are equal (as in this case) then the above expression simplified greatly. While the Volkersen solution is relatively easy to calculate it is not of very much practical use. This methodology does not take into account adherend bending and also this analytic solution makes the assumption that the adhesive will deform in shear and offer no axial stiffness $[17,18]$. These restrictions lead to a drastic underestimation of the actual shear stress in the joint, especially at the edges of longer joints, which was demonstrated in Figure 2.

A G-R solution which gives the shear stress for a single-lap joint in tensile loading via the following equation:

$$
\begin{aligned}
& \tau=\frac{p t}{8 c}\left\{\frac{\beta c}{t}(1+3 k) \frac{\cos \beta c / t \cdot x / c}{\sin \beta c / t}+3(1-k)\right\} \\
& \beta^{2}=8 \frac{G}{E} \frac{t}{\eta}
\end{aligned}
$$

where $p$ is the applied tensile pressure, $c$ is the half length of the overlap, $k$ is the moment factor and all other parameters are as before. This moment factor is found through tables given by Goland and Reissner [16] that correlate $k$ with the following quantity:

$$
\frac{c}{t} \sqrt{\frac{P}{E}}
$$

$k$ was obtained as 0.9033 for the applied tensile load of $10 \mathrm{MPa}$, and 0.7024 for that of $120 \mathrm{MPa}$.

The numerical model was developed following the specifications described in Section 2 for the case of a continuous titanium-titanium joint subjected to $10 \mathrm{MPa}$ tensile load. The obtained shear stress along the center of the adhesive bottom interface was plotted in Figure 2. It is clear that the numerical solution fitted the G-R solution much better than the Volkersen solution. As expected the Volkersen equation only predicted about $50 \%$ of the peak stress at the end of the adhesive layer obtained by Goland and Reissner. The predicted shear stress in the numerical model deviated from the G-R solution up to $14 \%$. This was due to the fact that the G-R equation assumed constant stress along the thickness and width, as well as constant flexural stiffness in the adhesive $[17,18]$, which did not capture the 3D, unsymmetrical effects, found in adhesive joints with square edges. More confined boundary conditions could lead to symmetrical behavior and thus reduced error between analytic solutions and the simulation.

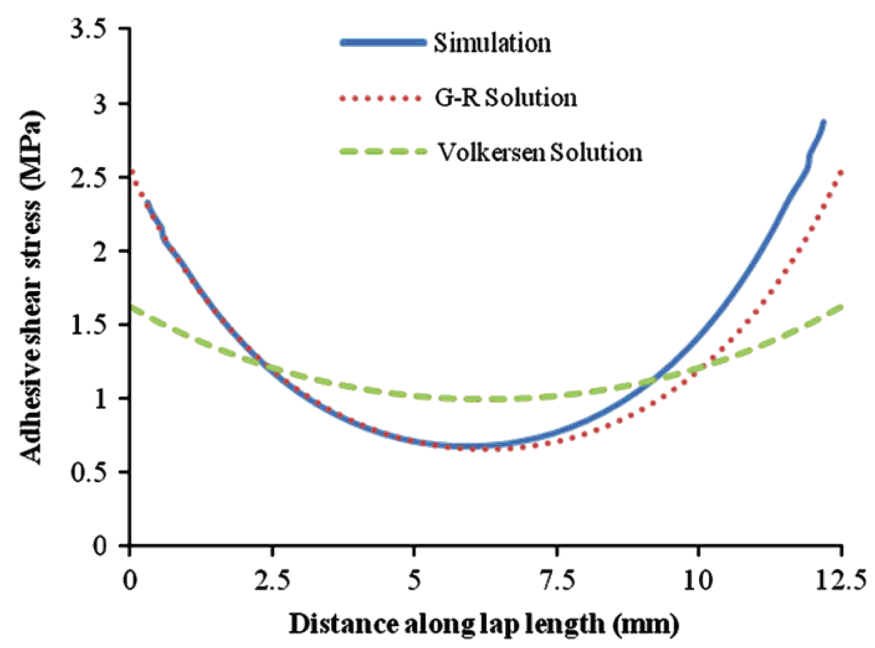

Figure 2. Comparison of adhesive shear stress for a titanium-titanium continuous joint subjected to $10 \mathrm{MPa}$ tension. 

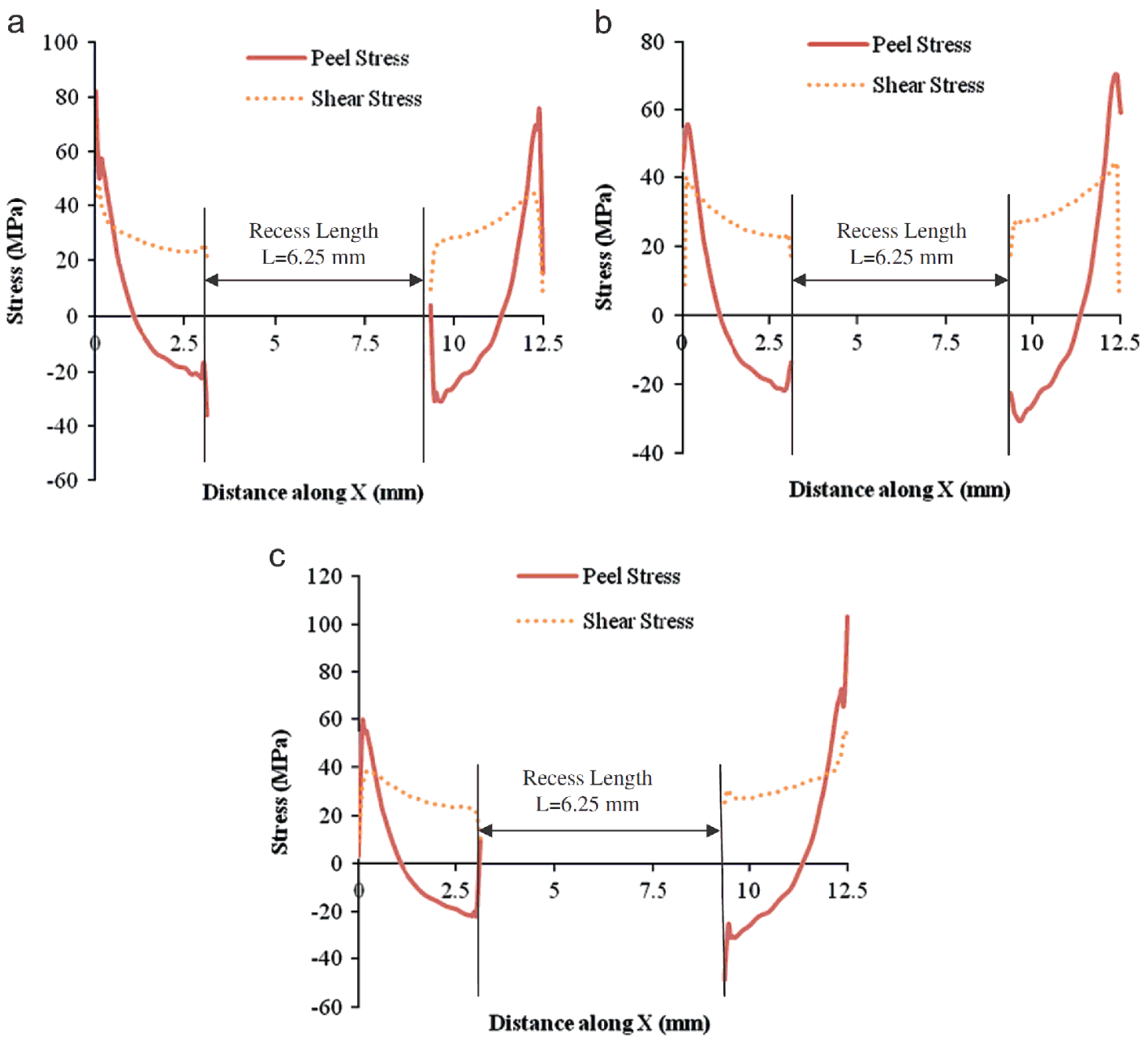

Figure 3. Distributions of peel and shear stresses along the middle line: (a) at the top interface bonded to the carbon/epoxy, (b) in the mid-layer and (c) at the bottom interface bonded to the titanium.

\subsection{Stress analysis in the adhesive}

The validated FE model can be extended to the carbon/epoxy to titanium bonded joint. The stress variations along the central line of the adhesive against the thickness were depicted in Figure 3. It is clear that stress distributions were asymmetric and the distribution of shear stress was much more uniform than the peel stress. The peak stress components always occurred near the adhesive outer edges ( $x=0$ and $x=12.5 \mathrm{~mm})$. This agreed with the recessed single-lap joint with similar adherends under tensile loading [1]. The peel stresses were obviously larger than the shear stresses, which indicated that the peel stress was the dominant component for the joint failure under tension. This was also observed for the stepped-lap adhesive joints with dissimilar adherends subjected to bending moments [19]. In addition, it was found that the stress components at the mid-layer were less than those at the top or bottom interfaces between the adhesive and adherends. Specifically the stress was more pronounced at the bottom interface bonded to titanium adherend. This may be caused by the dissimilar adherend as well as the out-of-plane bending (Figure 4). It was observed that increased loading led to the rotation of the overlapped area to realign loaded adherends, which induced the bending in the overlap. The single-lap joint extended $0.45 \mathrm{~mm}$ along the loading direction; in contrast, the peak displacement at the overlap zone was $2.6 \mathrm{~mm}$ along the $y$-direction. The peak bending occurred at the edge $x=12.5$ $\mathrm{mm}$, where the peak stress existed.
Figure 4. Bending effect for the recessed single-lap joint.

\subsection{Effect of adhesive material nonlinearity}

An elastic material model is typically used to represent the response of the adhesive layer in the joint analysis. Here we considered the plasticity of the adhesive. A linear hardening material model of the adhesive layer was adopted with a von Mises yield strength of $40 \mathrm{MPa}$ and hardening coefficient of 1 GPa [20]. As the applied tension increased, the occurrence of the maximum shear stress shifted from the overlap edge towards the inner adhesive region closer to the edges. This implied the formation and subsequent spread of the plastic zone in the adhesive once the stress reached its yield strength [21]. The snapshots of the adhesive plasticity zone during the linear ramping of the applied tension of $120 \mathrm{MPa}$ were shown in Figure 5. It was clear from the equivalent plastic strain map that the adhesive yielding zone initiated from both edges $(x=$ 0 and $x=12.5 \mathrm{~mm}$ ) and progressed toward to the center of the overlap. The yielding zone expanded with increased tension. The adhesive plasticity also led to the reduction of stress concentrations in the adhesive layer, as seen in Figure 6. It was obvious that the maximum principal stress at the bottom surface of the adhesive was mitigated especially at the edges $(x=0$ 
a
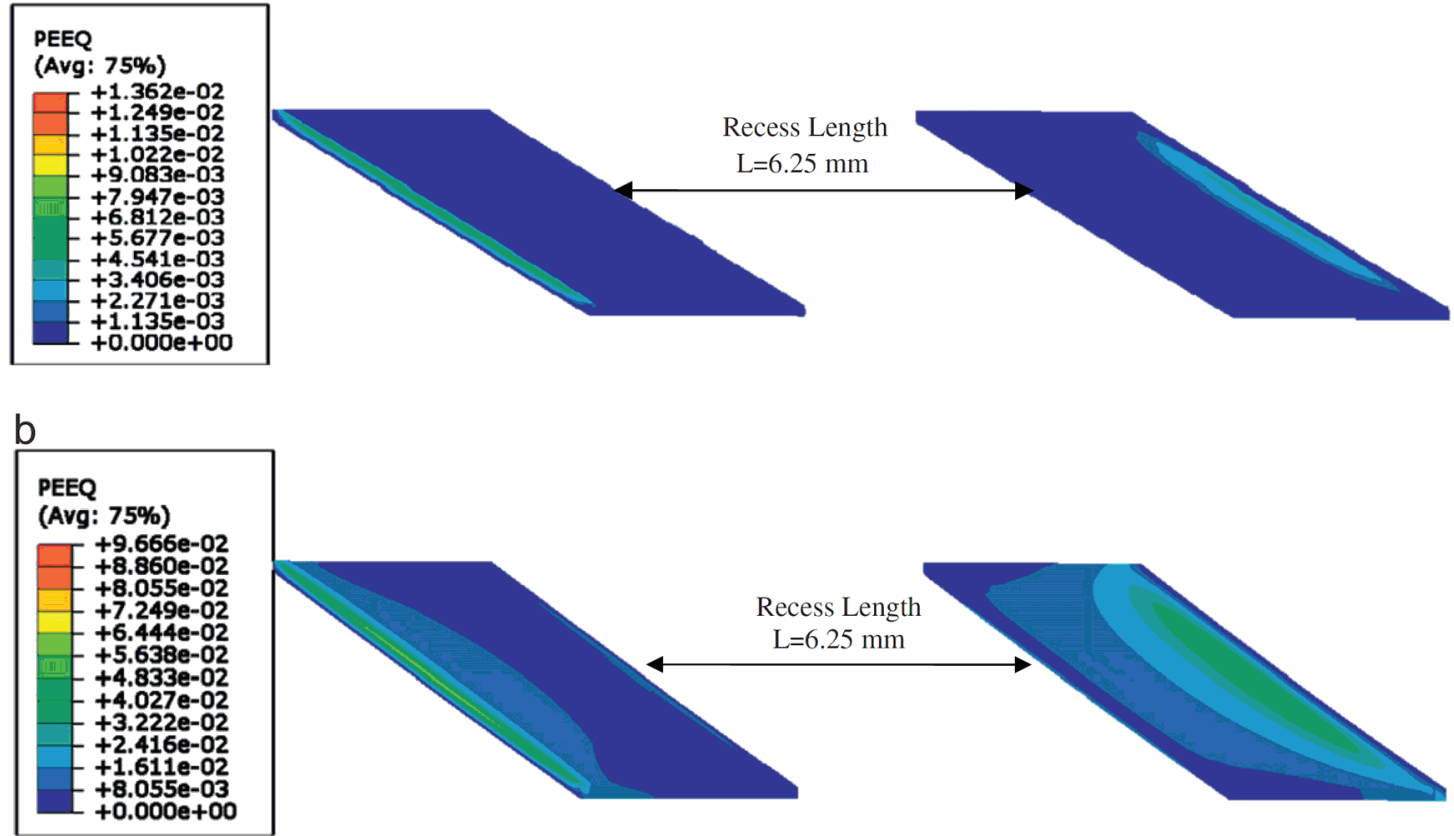

Figure 5. Distributions of equivalent plastic strain (PEEQ) in the adhesive layer at applied loading of (a) $72 \mathrm{MPa}$ and (b) $120 \mathrm{MPa}$.

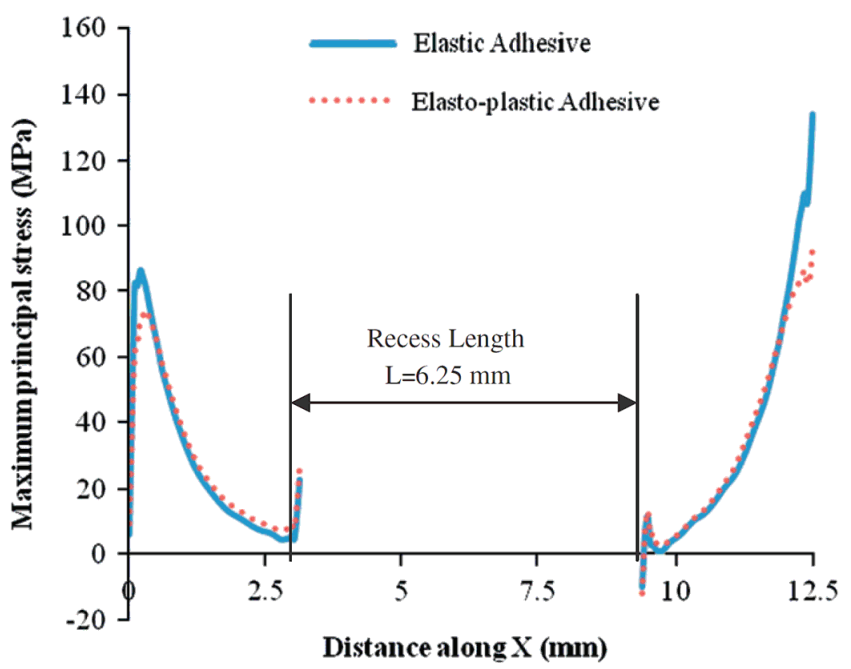

Figure 6. Effect of adhesive plasticity on the distribution of maximum principal stress at the bottom interface of the adhesive

and $x=12.5 \mathrm{~mm}$ ) of the adhesive layer. When the applied load reached $120 \mathrm{MPa}$, there was approximately a 30.3\% reduction in the maximum principal stress considering the hardening of the adhesive material. The plasticity induced stress mitigation was also observed in the continuous single-lap joint [22].

\subsection{Effect of adhesive spew fillet}

In practice, the adhesive joints do not have square ends [23]. A spew angle of 451 has been shown to mitigate the stress concentrations in a continuous single-lap joint [24-26]. The effect of an adhesive spew fillet with a 451 angle was also investigated in this work for the case of recessed single-lap joint. Figure 7 has shown the distribution of maximum principal stress at the bottom interface of the adhesive layer. It is apparent that the large stress gradient occurred at the recess ends including outer ones $(x=0$ and $x=12.5 \mathrm{~mm})$ and inner ones $(x$

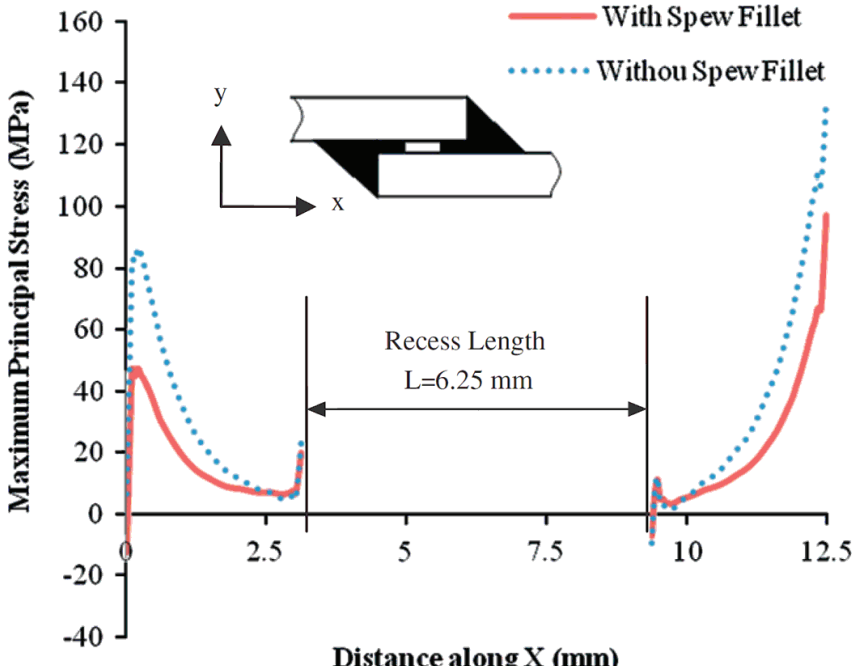

Distance along X (mm)

Figure 7. Effect of adhesive spew fillet on the distribution of maximum principal stress at the bottom interface of the adhesive.

$=3.125$ and $x=9.375 \mathrm{~mm}$ ), which was also observed by Lang and Mallick [1]. These results also demonstrated that the presence of a spew fillet led to the mitigation of stress concentrations at the recess outer ends, while the stress at the recess inner ends remained almost unchanged. There was about a $45.2 \%$ and a $27.5 \%$ reduction in the maximum principal stress at both outer edges of the adhesive layer considering the spew fillet. It is then expected that the strength of joints with an adhesive spew fillet was improved in comparison to that of joints with square ends.

\subsection{Effect of recess length in the adhesive}

A parametric study has been carried out to assess the reliability of the different recess lengths of an adhesive. In Figure 8, a comparison of the impact of various recess lengths on the distribution of maximum principal stress at the bottom in- 


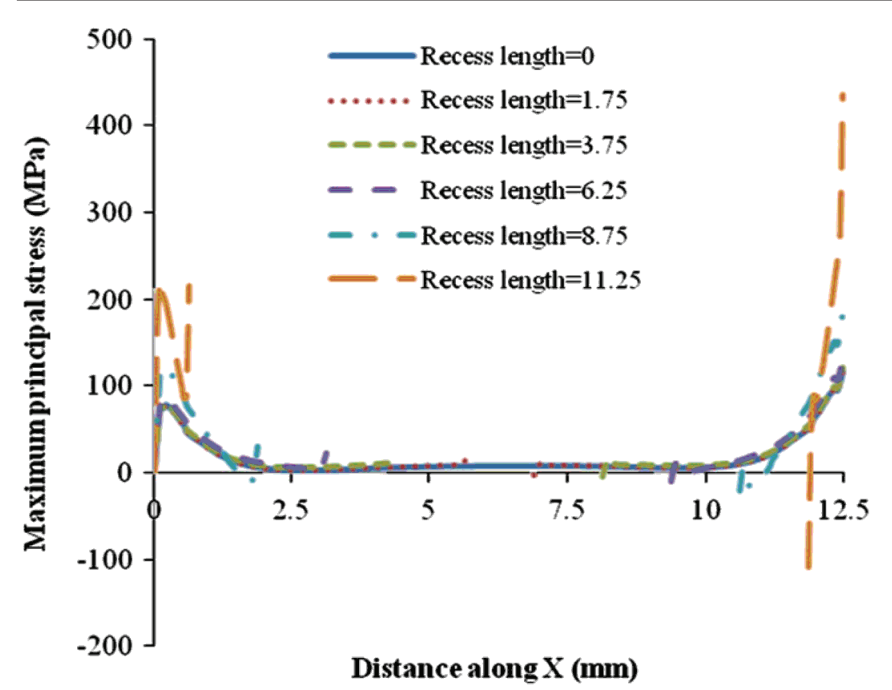

Figure 8. Effect of recess length on the distribution of maximum principal stress at the bottom surface of the adhesive.

terface of the adhesive layer was presented. The selected adhesive recess lengths of $L=1.25,3.75,6.25,8.75$ and 11.25 $\mathrm{mm}$ corresponded to $10 \%-90 \%$ of the overlap length in increments of $20 \%$, where $L=6.25 \mathrm{~mm}$, also as $50 \%$ of overlap length, was the case used in the previous numerical models. It was observed that the maximum principal stresses occurred at the edges of the adhesive layer, which was influenced by the length of the adhesive recess. Compared to the continuous adhesive with zero recess length, there was a marginal $0.6 \%$ and $3.6 \%$ increase of the maximum principal stress for the case of 1.25 and $3.75 \mathrm{~mm}$ recess length, respectively. When the recess length reached $6.25 \mathrm{~mm}$, the maximum principal stress increased $14.1 \%$. However, the maximum principal stress at the edges increased $56.5 \%$ and $270.7 \%$ for the cases of recess length of 8.75 and $11.25 \mathrm{~mm}$, respectively. These indicated that the stress concentrations in the adhesive layer are insensitive to a recess length less than $50 \%$ of overlap length. Furthermore, with the increase of the recess length, the stress gradient at the recess inner ends $(x=3.125$ and $x=9.375 \mathrm{~mm})$ became steeper.

\subsection{Evaluation of joint strength}

The joint strength was obtained as the load to initiate the crack propagation using XFEM through a built-in user subroutine UEL_XFEM. Instead of embedding a crack tip in the adhesive, the XFEM automatically introduces a new cohesive segment in the predefined enrichment nodes when the critical cohesive traction is reached. Cracks are introduced as jumps in the displacement fields, with their magnitude governed by the cohesive traction separation constitutive law $[12,14]$. The adhesive joints with various recess lengths including a zero one as well as the nonlinear spew fillet were investigated. A maximum principal stress of $50 \mathrm{MPa}$ was used to control the initiation of a crack. The fracture energy release rate was specified as $2 \mathrm{~N} / \mathrm{mm}$. In all the cases, cracks were found to initiate at the edge $(x=12.5 \mathrm{~mm})$ of the bottom interface of the adhesive layer, where the peak principal stresses occurred. It is clear from Figure 9 that the strength of recessed joints decreased slightly when the recess length was less than $6.25 \mathrm{~mm}(50 \%$ of the overlap length). The strength of the composite joint reduced $36.4 \%$ and $66.3 \%$ when the recess length reached 8.75

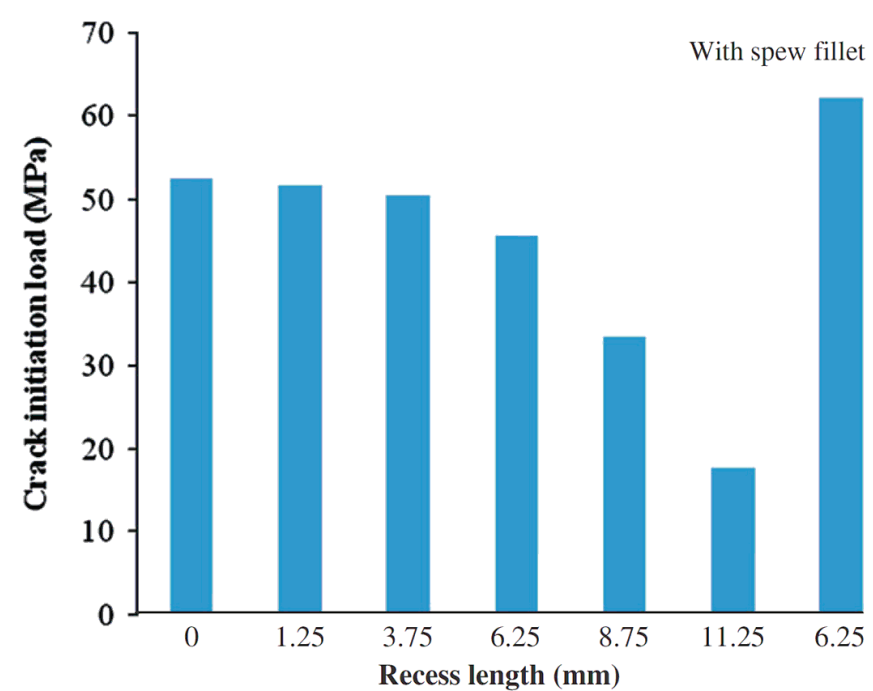

Figure 9. Comparison of crack initiation load for the recessed singlelap composite joints.

and $11.25 \mathrm{~mm}$, respectively. This could be attributed to the ductility of the adhesive $[27,28]$. It was obvious that adhesive spew fillet improved the joint strength by $36.3 \%$.

\section{Conclusion}

The performance of recessed single-lap joint with dissimilar adherends was investigated through the finite element method. After validation of the finite element models, the effects of material and geometrical nonlinearity of the adhesive as well as the effects of varying recess lengths were studied. The crack initiation and propagation through XFEM was used to assess the strength of the dissimilar composite joints. The initial condition of the adhesive was assumed as stress free without considering the cure temperature induced residual stresses. This simplification will alter the stress magnitude but not the conclusions obtained in this work, considering the comparative nature of this work. Our results can be summarized as follows:

(1) Large stresses occurred at the interfaces rather than the middle plane of the adhesive layer, which implied a limitation of analytical solutions.

(2) When the applied load reached $120 \mathrm{MPa}$, there was approximately a $30.3 \%$ reduction in the maximum principal stress considering the linear hardening of the adhesive material. The adhesive yielding zone initiated from both edges of the adhesive and progressed toward to the center of the overlap with the increased loading.

(3) The presence of a practical spew fillet reduced the peak stress concentrations by $45.2 \%$ and subsequently improved the strength of the joint by $36.3 \%$.

(4) Mitigation of stress concentration was observed in the cases of an adhesive layer with a recess length less than $6.25 \mathrm{~mm}$ or $50 \%$ of overlap length. The strength of recessed joints with a gap less than $50 \%$ of overlap length remained almost unchanged. This suggested a recess length of less than $6.25 \mathrm{~mm}$ may be beneficial for the performance of the joints.

Acknowledgments - The support funds of a NASA Nebraska Space Grant are gratefully acknowledged. 


\section{References}

[1] Lang TP, Mallick PK. The effect of recessing on the stresses in adhesively bonded single-lap joints. Int J Adhes Adhes 1999;19:257-71.

[2] Goncalves JPM, de Moura MFSF, Magalhaes AG, de Castro PMST. Application of interface finite elements to three-dimensional progressive failure analysis of adhesive joints. Fatigue Fract Eng Mater 2003;26:479-86.

[3] Narasimhan S, Shenoi RA, Jeong HK. Three-dimensional stresses in adhesively bonded lap joints with non-identical adherends. Proc Inst Mech Eng, Part L: J Mater 2004;218:283-98.

[4] Ribeiro FL, Borges L, d'Almeida JRM. Numerical stress analysis of carbonfibre- reinforced epoxy composite single-lap joints. Int J Adhes Adhes 2011;31:331-7.

[5] Liao LJ, Kobayashi T, Sawa T, Goda Y. 3-D FEM stress analysis and strength evaluation of single-lap adhesive joints subjected to impact tensile loads. Int J Adhes Adhes 2011;31:612-9.

[6] Mattos HSD, Sampaio EM, Monteiro AH. Static failure analysis of adhesive single lap joints. Int J Adhes Adhes 2011;31:446-54.

[7] Rossettos JN, Lin P, Nayebhashemi H. Comparison of the effects of debonds and voids in adhesive joints. J Eng Mater Tech: Asme 1994;116:533-8.

[8] Rossettos JN, Zang E. On the peak shear stresses in adhesive joints with voids. J Appl Mech and Tech: Asme 1993;60:559-60.

[9] Olia M, Rossettos JN. Analysis of adhesively bonded joints with gaps subjected to bending. Int J Solids Struct 1996;33:2681-93.

[10] Mazumdar SK, Mallick PK. Static and fatigue behavior of adhesive joints in SMC-SMC composites. Polym Compos 1998;19:139-46.

[11] Belytschko T, Black T. Elastic crack growth in finite elements with minimal remeshing. Int J Numer Meth Eng 1999;45:601-20.

[12] Giner E, Sukumar N, Tarancon JE, Fuenmayor FJ. An Abaqus implementation of the extended finite element method. Eng Fract Mech 2009;76:347-68.

[13] Baker A, Dutton S, Kelly D. Composite materials for aircraft structures, 2nd ed. American Institute of Aeronautics and Astronautics, 2004.

[14] ABAQUS v6.10 documentation, Dassault Systèmes Simulia Corp., Providence, RI, 2011.
[15] Volkersen O. Die Nietkraftverteilung in zugbeanspruchten Nietverbindungen mit konstanten Laschenquerschnitten. Luftfahrtforschung 1938;15:41-7.

[16] Goland M, Reissner E. The stresses in cemented joints. J Appl Mech 1944;66:A17-27.

[17] da Silva LFM, das Neves PJC, Adams RD, Spelt JK. Analytical models of adhesively bonded joints. Part I: literature survey. Int J Adhes Adhes 2009;29:319-30.

[18] da Silva LFM, das Neves PC, Adams RD, Wang A, Spelt JK. Analytical models of adhesively bonded joints. Part II: comparative study. Int J Adhes Adhes 2009;29:331-41.

[19] Sawa T, Ichikawa K, Shin Y, Kobayashi T. A three-dimensional finite element stress analysis and strength prediction of stepped-lap adhesive joints of dissimilar adherends subjected to bending moments. Int J Adhes Adhes 2010;30:298-305.

[20] Kumar S, Pandey PC. Fatigue life prediction of adhesively bonded single lap joints. Int J Adhes Adhes 2011;31:43-7.

[21] Pandey PC, Narasimhan S. Three-dimensional nonlinear analysis of adhesively bonded lap joints considering viscoplasticity in adhesives. Comput Struct 2001;79:769-83.

[22] Goncalves JPM, de Moura MFSF, de Castro PMST. A three-dimensional finite element model for stress analysis of adhesive joints. Int J Adhes Adhes 2002;22:357-65.

[23] Tsai MY, Morton J. The effect of a spew fillet on adhesive stress distributions in laminated composite single-lap joints. Compos Struct 1995;32:123-31.

[24] Belingardi G, Goglio L, Tarditi A. Investigating the effect of spew and chamfer size on the stresses in metal/plastics adhesive joints. Int J Adhes Adhes 2002;22:273-82.

[25] Grant LDR, Adams RD, da Silva LFM. Experimental and numerical analysis of single-lap joints for the automotive industry. Int J Adhes Adhes 2009;29:405-13.

[26] da Silva LFM, Adams RD. Techniques to reduce the peel stresses in adhesive joints with composites. Int J Adhes Adhes 2007;27:227-35.

[27] da Silva LFM, Critchlow GW, Figueiredo MAV. Parametric study of adhesively bonded single lap joints by the Taguchi method. J Adhes Sci Technol 2008;22:1477-94.

[28] da Silva LFM, Carbas RJC, Critchlow GW, Figueiredo MAV, Brown K. Effect of material, geometry, surface treatment and environment on the shear strength of single lap joints. Int J Adhes Adhes 2009;29:621-32. 